\title{
SOBRE VÍDEOS DO YOUTUBE RELACIONADOS À CONFECÇÃO DE IMPLEMENTOS ADAPTADOS PARA O ENSINO DO ATLETISMO NA ESCOLA $^{1}$
}

\author{
Thiago Lucas De Castro \\ Universidade Estadual Paulista, Rio Claro, São Paulo, Brasil. \\ Sara Quenzer Matthiesen \\ Universidade Estadual Paulista, Rio Claro, São Paulo, Brasil. \\ Guy Ginciene \\ Universidade Federal do Rio Grande do Sul, Porto Alegre, Rio Grande do Sul, Brasil.
}

\begin{abstract}
Resumo
Com o objetivo de investigar vídeos do Youtube sobre implementos adaptados de atletismo, esta pesquisa teve duas etapas: 1. identificação de vídeos sobre a confecção de implementos adaptados ao atletismo; 2 . catalogação dos vídeos, organizando-se um banco de dados. No total, foram 28 os vídeos do Youtube, sendo: 6 de barreira, 4 de martelo, 6 de dardo, 2 de disco, 5 de peso, 2 de bastão, 1 de raia e 2 que envolvem a confecção de dois ou mais implementos, organizados em duas categorias de acordo com as características dos materiais. Os resultados revelaram que os vídeos do Youtube podem contribuir como um recurso importante para a difusão e a confecção de implementos adaptados, utilizando-se diferentes materiais que ampliam as possibilidades de ensino desse conteúdo na escola.
\end{abstract}

Palavras-chave: Atletismo. Educação Física. Ensino.

\section{Introdução}

O atletismo é reconhecido como um esporte-base que aborda habilidades motoras fundamentais, as quais, de acordo com Holderbaum (2012, p. 1), podem ser divididas em dois grandes grupos: "habilidades locomotoras" (correr, marchar, saltar) e "habilidades manipulativas" (arremessar, lançar), também utilizadas em outras modalidades esportivas, tais como: futebol, handebol e voleibol. Logo, praticar atletismo implica melhorar as habilidades fundamentais que serão utilizadas em vários esportes e em situações da vida cotidiana, fato que o torna fundamental para crianças e jovens.

Apesar disso, o atletismo é um dos conteúdos pouco desenvolvidos em aulas de Educação Física, fato que parece se justificar pela falta de material e de espaço físico adequado (LENCINA e ROCHA JÚNIOR, 2001; JUSTINO e RODRIGUES, 2007; MATTHIESEN, 2005; 2007; 2014; ORO, 1983; ROLIM e COLAÇO, 2002; SILVA e DARIDO, 2011). Ou seja, a falta de material específico - leia-se implemento oficial - consiste em um dos motivos para que o atletismo não seja ensinado, afinal, como lembra Matthiesen (2007), alguns professores consideram que sem ele o aluno não conseguiria aprender essa modalidade esportiva.

${ }^{1}$ Auxílio: CNPQ-PIBITI (2015-2016). 
Diante desse quadro, uma boa opção seria a adaptação dos implementos a serem utilizados no ensino do atletismo. Logo, uma solução para a substituição dos implementos oficiais são os implementos "adaptados", também denominados como "alterativos", feitos com materiais de menor custo e que, na maioria das vezes, são recicláveis (garrafas pet, papelão, jornal, sacolas plásticas), além de serem de fácil acesso (pedras, meia-calça, canos de PVC, cabo de vassoura). Complementando, Matthiesen (2014) enfatiza que os implementos adaptados são mais leves, podem ser utilizados em espaço reduzido, propiciam menos risco, além de serem baratos, viabilizando sua confecção.

Enfim, pode-se dizer que as principais diferenças entre os implementos oficiais do atletismo e os implementos adaptados/alternativos são: peso, tamanho e preço. Ou seja, o primeiro atende às normas e padrões estabelecidos pela International Association of Athletics Federations (IAAF), instituição que tem como meta estabelecer as regras que regem essa modalidade esportiva, que estão vinculados aos avanços tecnológicos atuais em torno da melhor matéria-prima para a sua produção. Logo, nota-se que os implementos oficiais são mais pesados, maiores e mais caros, enquanto os segundos, isto é, os implementos adaptados/alternativos, são mais leves e baratos, utilizando, algumas vezes, materiais recicláveis. Quanto à sua confecção, podem ser feitos em sala de aula, com alunos de qualquer faixa etária, e o professor tem a oportunidade de utilizar esse momento para inserir conhecimentos relacionados à história do atletismo, ao surgimento da prova, tratando das particularidades em torno do implemento utilizado e ampliando, com isso, os conhecimentos acerca desta modalidade esportiva.

Iniciativas neste sentido têm sido desenvolvidas, inclusive com o auxílio da Tecnologia da Informação e Comunicação (TIC), razão pela qual o objetivo desta pesquisa foi investigar, dentre os vídeos disponíveis no site do YouTube, diferentes possibilidades de confecção de implementos adaptados ao ensino do atletismo, identificando aqueles capazes de subsidiar o professor de Educação Física no ensino dessa modalidade esportiva. A ideia é que o banco de dados elaborado a partir desta pesquisa possa, assim como as demais sugestões de materiais alternativos, contribuir para que o atletismo seja ensinado na escola, independentemente das condições físicas e de materiais existentes.

\section{Metodologia}

Para alcançar o objetivo proposto, esta pesquisa foi baseada no método de revisão sistemática de literatura (MESQUITA et al., 2013), a qual, segundo Parra Filho e Santos (1998), Santos (1999) e Severino (2000), não se restringe a livros e artigos, mas pode se estender a outros tipos de fontes, como a própria internet. Nesse sentido, adequamos esse mesmo método a um website de busca, para uma revisão sistemática de vídeos, com base em três etapas, a saber: (1) delimitação da pesquisa; (2) condução da pesquisa; (3) conclusões e divulgação dos resultados (MESQUITA et al., 2013).

A primeira etapa contou com três delimitações importantes: o "objetivo", a "equação" e o "âmbito" da pesquisa (MESQUITA et al., 2013). O "objetivo" consistiu em investigar, dentre os vídeos disponíveis no site do YouTube, diferentes possibilidades de confecção de implementos adaptados ao ensino do atletismo, identificando aqueles capazes de subsidiar o professor de Educação Física no ensino dessa modalidade esportiva. A "equação", que se refere às palavras utilizadas na busca, restringiu-se a: "material de atletismo adaptado", "atletismo escolar adaptado" e "material de atletismo alternativo", enquanto o "âmbito", que se refere ao local em que a pesquisa foi realizada, foi, no caso desta pesquisa, o YouTube, o primeiro, em 2016, dentre as 100 ferramentas mais utilizadas na Educação para a busca de vídeos (C4LPT, 2017). 
Após a busca pelos vídeos, foram definidos e aplicados, na segunda etapa: os critérios de inclusão; os critérios de exclusão; os critérios de validade; os resultados (registrados com endereço e breve descrição), e a filtragem dos resultados (após a aplicação de todos os critérios de seleção e registros).

Os critérios para a seleção e a exclusão, definidos inicialmente, restringiram muito o número de vídeos identificados, considerando-se que a ideia foi partir de uma ampla pesquisa, a fim de coletarmos vídeos que: tratassem da confecção de implementos adaptados para o atletismo; fossem em língua portuguesa; tivessem duração de até 5 minutos; utilizassem materiais reciclados ou de baixo custo. Entretanto, para a nossa surpresa, nos defrontamos com o fato de haver no YouTube pouco material referente ao assunto, reforçando, portanto, a importância de se confeccionar vídeos e disponibilizá-los amplamente. Assim, com base no exposto, consideramos não ser oportuno aplicarmos tais critérios, já que isso reduziria, ainda mais, o material coletado, restringindo a pesquisa. Sendo assim, optamos por inserir todos os vídeos identificados sobre a confecção de implementos alternativos para o atletismo.

$\mathrm{Na}$ terceira etapa, foram elaborados os planos para a apresentação dos resultados (MESQUITA et al., 2013), cujos dados foram analisados e agrupados, de acordo com suas características, organizando-se um banco de dados visando ampliar a divulgação, como veremos, dos resultados desta pesquisa.

\section{Resultados}

De modo geral, foram identificados 28 vídeos específicos sobre a confecção de implementos alternativos, organizando-se um banco de dados de acordo com os implementos utilizados em cada prova do atletismo, sendo eles: 6 sobre a barreira, 4 sobre o martelo, 6 sobre o dardo, 2 sobre o disco, 5 sobre o peso, 2 sobre o bastão de revezamento, 1 sobre a raia e 2 que demonstram a confecção de dois ou mais implementos, totalizando 28 vídeos (Figura 1).

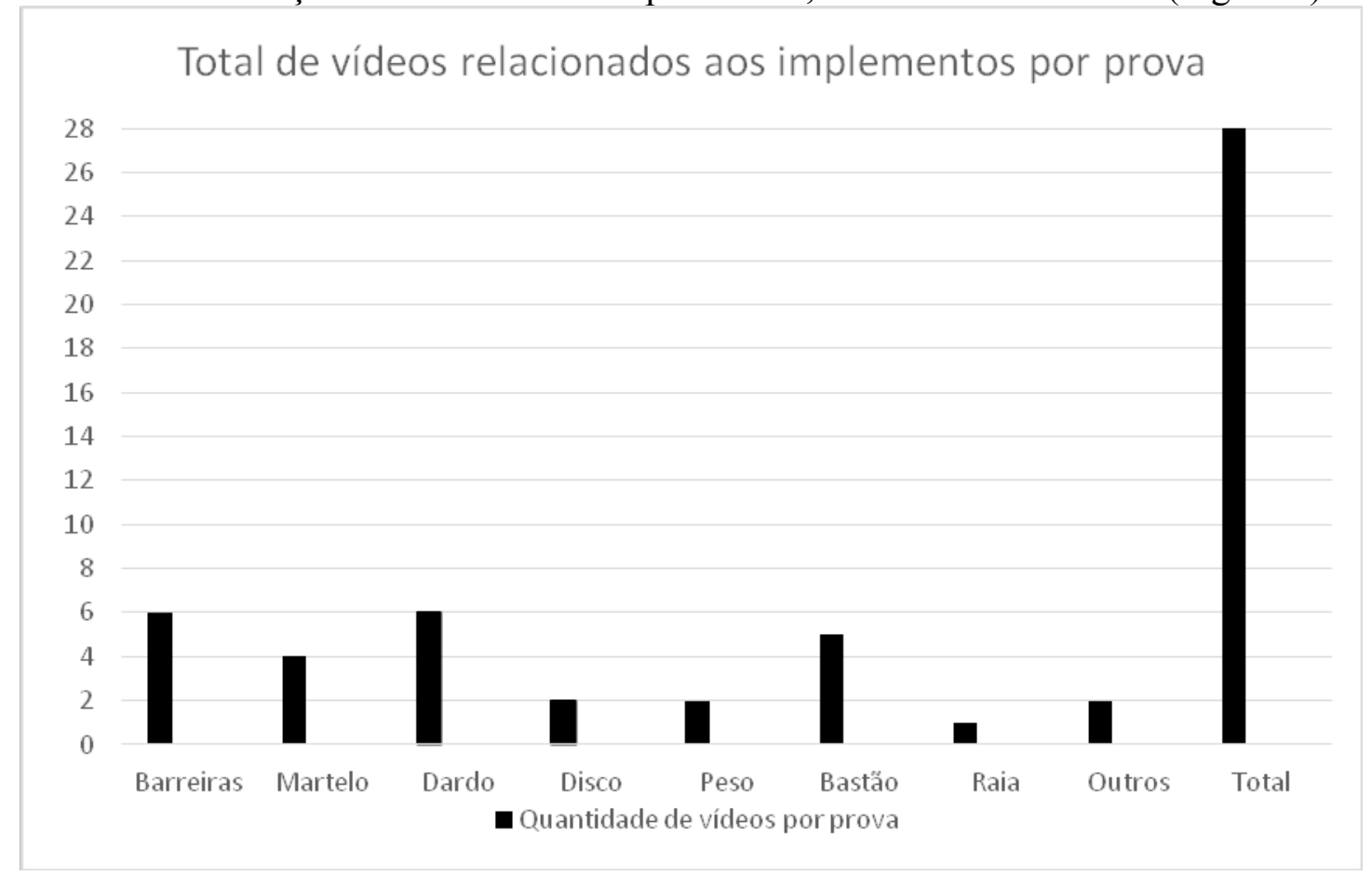

Figura 1: Vídeos relacionados aos implementos por prova.

Fonte: Os autores, 2017

Obervando-se a Figura 1, nota-se que há vídeos do YouTube relacionados à confecção de diferentes implementos do atletismo, que favorecem o ensino de diferentes conteúdos, tais 
como: corridas rasas, corridas com barreiras, corridas com obstáculos, marcha atlética, revezamentos, arremesso, lançamentos e provas combinadas.

Comparando os vídeos encontrados com as provas de atletismo que poderiam ser ensinadas para crianças e jovens, observamos que os saltos (em altura, em distância, triplo e com vara) não apareceram no conjunto de vídeos identificados no YouTube. Contudo, cabe lembrar que a caixa de areia (salto em distância e triplo); os postes e o sarrafo (salto em altura e com vara); a vara (salto com vara) também poderiam ser adaptados visando ao ensino do atletismo, sobretudo, na escola.

Prosseguindo na análise dos vídeos, observamos duas características marcantes:

(1) vídeos que explicitam a necessidade de utilização de recursos diversos, tais como: ferramentas cortantes e perfurantes, dificultando a confecção do material sem que haja a presença de um adulto ou que necessitem de preparação por um adulto para cortar, serrar, costurar, colar e derreter materiais diversos;

(2) vídeos que explicitam a utilização de materiais adaptados e/ou recicláveis, cuja confecção é bastante simples e pode ser realizada pelos próprios alunos.

Nesse sentido, os vídeos que integram o banco de dados foram agrupados e descritos nessas duas categorias.

Dos 28 vídeos analisados, 15 se encaixam na Categoria 1. O fato de esses vídeos estarem nesse grupo não invalida a confecção dos implementos em sala de aula. Embora utilizem ferramentas perfurantes e cortantes, o professor, para garantir a segurança dos alunos, poderá auxiliar a confeccioná-los, evitando maiores riscos, além de propiciar aos alunos a interação com o implemento que utilizarão em aula.

O Quadro 1 apresenta os 15 vídeos selecionados na Categoria 1, contendo uma breve descrição e o endereço para acesso de outros interessados.

Quadro 1: Vídeos integrantes da Categoria 1

\begin{tabular}{|c|l|}
\hline \multicolumn{2}{|c|}{ Categoria 1 } \\
\hline Vídeo & \multicolumn{1}{c|}{ Endereço e breve descrição } \\
\hline 1 & $\begin{array}{l}\text { O vídeo https://www.youtube.com/watch?v=qlJuKyMSeRA trata da confecção } \\
\text { de uma barreira com canos, tubos e conectores de PVC, material que precisa ser } \\
\text { comprado, gerando um certo custo. Nota-se a necessidade de utilização de um } \\
\text { aparelho perfurante, como uma furadeira. Assim, sugerimos que o professor faça } \\
\text { os furos, facilitando a confecção do material, além de evitar riscos. }\end{array}$ \\
\hline 2 & $\begin{array}{l}\text { O vídeo https://www.youtube.com/watch?v=SJD6YFnLyUU trata da confecção } \\
\text { de uma barreira com materiais tais como: canos de PVC, conectores de PVC, } \\
\text { cola para cano PVC, além de serra para corte do material. Caso o professor quei- } \\
\text { ra confeccionar a barreira nas aulas de Educação Física, sugere-se que leve os ca- } \\
\text { nos medidos e cortados, deixando a montagem do material para os alunos. }\end{array}$ \\
\hline 3 & $\begin{array}{l}\text { O vídeo https://www.youtube.com/watch?v=LOh7fRHINzQ trata da confecção } \\
\text { de uma barreira com materiais tais como: canos de PVC, conectores de PVC, } \\
\text { cola para cano PVC e fitas adesivas coloridas. O material precisa ser serrado, de } \\
\text { modo a adquirir as dimensões corretas da barreira, mas, sem deixar de se levar } \\
\text { em conta a altura dos alunos. }\end{array}$ \\
\hline 4 & $\begin{array}{l}\text { O vídeo https://www.youtube.com/watch?v=3pV6C22KKg8 trata da confecção } \\
\text { de um martelo com materiais tais como: bola de plástico (semelhante às de pisci- } \\
\text { nas de bolinhas infantis), fita de tecido, linha e agulha. Dada a necessidade de } \\
\text { utilização de agulhas, sugere-se que a confecção do material seja feita por um } \\
\text { adulto, com auxílio dos alunos. }\end{array}$ \\
\hline 5 & \begin{tabular}{l} 
O vídeo https://www.youtube.com/watch?v=5EGLd3Y4NCc trata da confecção \\
\hline
\end{tabular} \\
\hline
\end{tabular}




\begin{tabular}{|c|c|}
\hline & $\begin{array}{l}\text { do martelo com: areia grossa, meia de nylon, fita de tecido, agulhas, linhas e sa- } \\
\text { colas plásticas. Dada a necessidade de utilização de agulhas, sugere-se que a con- } \\
\text { fecção do material seja feita por um adulto, com auxílio dos alunos. }\end{array}$ \\
\hline 6 & $\begin{array}{l}\mathrm{O} \text { vídeo https://www.youtube.com/watch? } \mathrm{v}=\mathrm{kjVz} \text { htCfaI trata da confecção do } \\
\text { dardo com materiais tais como: garrafas pet, cabo de vassoura, fita crepe, fitas } \\
\text { adesivas coloridas, corda, cano de PVC, além das seguintes ferramentas: serra, } \\
\text { alicate, caneta, estilete, tesoura, cola instantânea, fogão, panela e água. Dada a } \\
\text { necessidade de utilização de materiais específicos, que envolvem certos riscos, } \\
\text { sugere-se que a confecção do material seja feita por um adulto, com auxílio dos } \\
\text { alunos. }\end{array}$ \\
\hline 7 & $\begin{array}{l}\text { O vídeo https://www.youtube.com/watch? } \mathrm{v}=\text { wppuohafIVY trata da confecção do } \\
\text { dardo com materiais tais como: cabo de vassoura, estilete, tintas e pincel. O uso } \\
\text { do estilete é imprescindível para talhar a ponta do implemento, de modo que } \\
\text { deve ser feito por um adulto. Sugere-se que o professor providencie o cabo de } \\
\text { vassoura com a ponta talhada para que os alunos possam pintar o implemento. }\end{array}$ \\
\hline 8 & $\begin{array}{l}\text { O vídeo https://www.youtube.com/watch?v=nIRYv3me-B4 trata da confecção } \\
\text { do dardo com materiais, tais como: cabo de vassoura, tesoura, fita de tecido, } \\
\text { cola, tintas e pincel. No vídeo, sugere-se que a ponta do implemento seja talhada } \\
\text { com um estilete ou que se insira um acessório de plástico com a mesma função. }\end{array}$ \\
\hline 9 & $\begin{array}{l}\mathrm{O} \text { vídeo } \mathrm{https}: / / \mathrm{www} . \text { youtube.com } / \text { watch? } \mathrm{v}=1 \mathrm{gkJekt} 4 \mathrm{dvE} \text { trata da confecção do } \\
\text { dardo com materiais tais como: cano de PVC, papel adesivo colorido, serra e te- } \\
\text { soura. }\end{array}$ \\
\hline 10 & $\begin{array}{l}\mathrm{O} \text { vídeo https://www.youtube.com/watch? } \mathrm{v}=\mathrm{nRvCSN7VHfI} \text { trata da confecção } \\
\text { do dardo utilizando: cano de PVC e bolinha de tênis. Para a sua confecção, é ne- } \\
\text { cessário abrir a bolinha com um estilete, fato que demanda cuidados, suge- } \\
\text { rindo-se que o professor o faça, evitando maiores riscos. }\end{array}$ \\
\hline 11 & 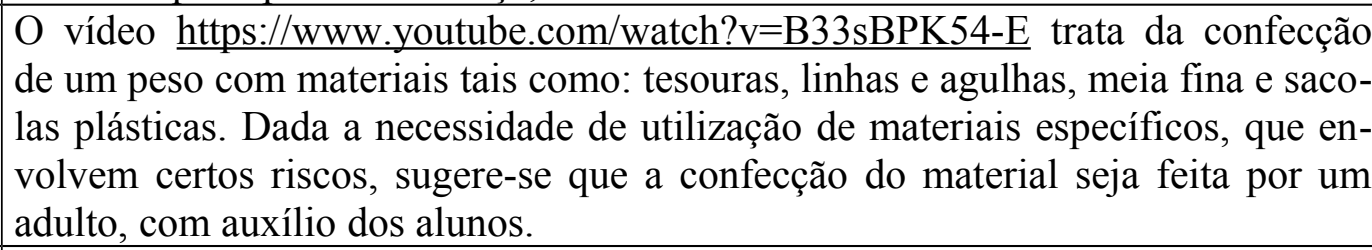 \\
\hline 12 & $\begin{array}{l}\text { O vídeo https://www.youtube.com/watch?v=jMPK236Tzf4 trata da confecção } \\
\text { do peso utilizando-se materiais específicos, tais como: areia grossa, meia de ny- } \\
\text { lon, agulha e linha, sacola preta e branca. O implemento é simples de ser feito, } \\
\text { mas, dada a necessidade da agulha para costurar a meia de nylon, sua confecção } \\
\text { fica limitada, dificultando sua realização nas aulas de Educação Física. }\end{array}$ \\
\hline 13 & $\begin{array}{l}\text { O vídeo https://www.youtube.com/watch?v=6-n6bmzrATI trata da confecção do } \\
\text { bastão utilizado nas corridas de revezamento utilizando-se materiais específicos, } \\
\text { tais como: cabo de vassoura, fita de tecido, tintas, cola de madeira, pincéis, serro- } \\
\text { te tesoura e fita métrica. O implemento é fácil de ser construído e pode ser provi- } \\
\text { denciado pelo professor, evitando-se riscos. Consiste no corte de um cabo de } \\
\text { vassoura no tamanho desejado e com decoração, tornando-o mais atrativo. }\end{array}$ \\
\hline 14 & $\begin{array}{l}\text { O vídeo https://www.youtube.com/watch?v=0j3uSBuNT5E trata da confecção } \\
\text { de diversos materiais, tais como: barreira, bastão, peso e dardo. No geral, foram } \\
\text { utilizados canos de PVC e fita adesiva coloridas, possibilitando sua confecção } \\
\text { nas aulas de Educação Física. Confeccionado por meio de fotos, alguns detalhes } \\
\text { não são visíveis, embora demonstre ser de fácil produção. }\end{array}$ \\
\hline 15 & $\begin{array}{l}\mathrm{O} \text { vídeo } \underline{\mathrm{https}: / / \text { www.youtube.com/watch? } \mathrm{v}=\mathrm{vJvLMw} 72 \mathrm{cys}} \text { trata da confecção } \\
\text { do bloco de partida e do peso. Os materiais utilizados foram: blocos de madeira, } \\
\text { tinta spray, meia, fita adesiva e ferramentas, tais como: serra elétrica, tesoura, es- }\end{array}$ \\
\hline
\end{tabular}




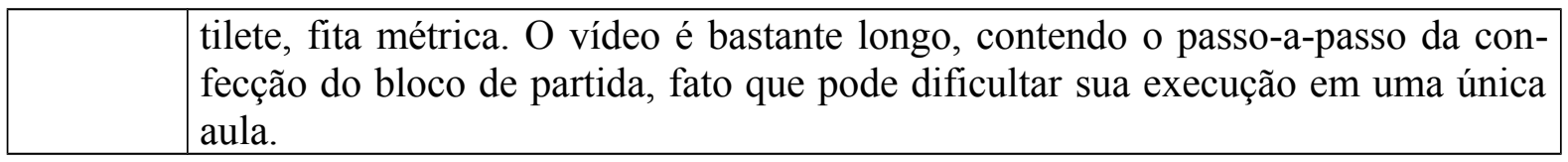

Fonte: Os autores, 2017

Esse conjunto de vídeos da Categoria 1 pode ser bastante útil ao professor na preparação de suas aulas. Por serem vídeos que apresentam confecções mais sofisticadas - e, até mesmo, perigosas em alguns casos -, este conjunto de vídeos demanda a presença do professor, que parece ter um papel fundamental neste processo. Este pode preparar o material antes (sozinho) ou durante a aula (com os alunos), suprindo as deficiências estruturais existentes.

Dessa forma, se o professor quiser organizar uma aula de corridas com barreiras, por exemplo, ele poderá utilizar o vídeo de duas formas. Na primeira, poderá confeccioná-las antes da aula e assim ensinar os saberes corporais e conceituais dessa prova. Na segunda forma de utilização, o professor poderá, juntamente com os alunos, confeccionar a barreira durante a aula, ensinando, entre outras coisas: diferentes formas de adaptações do implemento oficial; discutir questões ambientais sobre o reaproveitamento de materiais (reciclagem); formas de adaptação/adequação do esporte institucionalizado para possibilitar sua prática em outros locais, como o próprio bairro em que moram os alunos.

Já os 13 vídeos que integram a Categoria 2, descritos no Quadro 2, favorecem a sua reprodução em sala de aula, propiciando a confecção dos implementos (alternativos/adaptados) do atletismo pelos próprios alunos.

Quadro 2: Vídeos integrantes da Categoria 2

\begin{tabular}{|c|l|}
\hline Categoria 2 \\
\hline Vídeo & \multicolumn{1}{|c|}{ Endereço e breve descrição } \\
\hline 1 & $\begin{array}{l}\text { O vídeo https://www.youtube.com/watch?v=RHSIJxrBvTg trata da confecção } \\
\text { de uma barreira com materiais tais como: espaguetes (flutuadores utilizados na } \\
\text { natação em forma de cilindro), elásticos e braçadeiras de nylon. Apesar do cus- } \\
\text { to, essa é uma boa opção de material, dados a sua flexibilidade e seu baixo } \\
\text { indice de riscos. }\end{array}$ \\
\hline 2 & $\begin{array}{l}\text { O vídeo https://www.youtube.com/watch?v=ZOk3S EsoeU trata da confecção } \\
\text { da barreira. Os materiais utilizados foram: canos de PVC e conectores do tipo } \\
\text { "cotovelos", também em PVC. Não utiliza nenhuma ferramenta perfurante em } \\
\text { sua confecção, desde que os canos já estejam em tamanhos adequados, de } \\
\text { modo que pode ser produzido em sala de aula. }\end{array}$ \\
\hline 3 & $\begin{array}{l}\text { O vídeo https://www.youtube.com/watch?v=qCkoScB4qDA trata da confecção } \\
\text { de um martelo com materiais tais como: corda, braçadeiras de nylon, tubo de } \\
\text { alumínio, fita crepe, meia com areia dentro e uma bolsa de tecido que precisa } \\
\text { ser resistente, feita, de preferência, por uma costureira. }\end{array}$ \\
\hline 4 & $\begin{array}{l}\text { O vídeo https://www.youtube.com/watch?v=gCVkpsnphMA trata da confecção } \\
\text { do martelo para o lançamento do martelo. Os materiais utilizados foram: meia- } \\
\text { calça, pedra, jornal, sacola plástica. Bem explicativo, o vídeo propicia que o } \\
\text { material seja confeccionado em aulas de Educação Física. }\end{array}$ \\
\hline 5 & $\begin{array}{l}\text { O vídeo https://www.youtube.com/watch?v=r0akGCk i2k trata da confecção } \\
\text { do dardo para o lançamento do dardo. Os materiais utilizados foram: espague- } \\
\text { tes (flutuadores utilizados na natação em forma de cilindro), pedaços de tecido } \\
\text { tipo TNT, bolinha de tênis, braçadeira de nylon e fita adesiva. O implemento }\end{array}$ \\
\hline
\end{tabular}




\begin{tabular}{|c|c|}
\hline & $\begin{array}{l}\text { não utiliza ferramentas que possam ferir as crianças, logo pode ser confeccio- } \\
\text { nado em aulas de Educação Física. }\end{array}$ \\
\hline 6 & $\begin{array}{l}\mathrm{O} \text { vídeo https://www.youtube.com/watch?v=YoUhFOXkcVc trata da confec- } \\
\text { ção de um disco com materiais tais como: pratinhos de alumínio, retalhos de } \\
\text { câmara de ar e fita crepe. Com exceção dos pratinhos de alumínio, o restante do } \\
\text { material tem custo reduzido. Ou seja, a fita crepe pode ser adquirida pela escola } \\
\text { enquanto os retalhos da câmara de ar podem ser adquiridos gratuitamente em } \\
\text { borracharias. }\end{array}$ \\
\hline 7 & $\begin{array}{l}\mathrm{O} \text { vídeo https://www.youtube.com/watch? } \mathrm{v}=\mathrm{GFUvk} 5 \mathrm{xyLw} \\
\text { de um disco com materiais tais como: pratinhos de papelão, jornal, pedrinhas, } \\
\text { canetas para colorir, fita adesiva e tesoura sem ponta. }\end{array}$ \\
\hline 8 & $\begin{array}{l}\mathrm{O} \text { vídeo https://www.youtube.com } / \text { watch? } \mathrm{v}=0 \mathrm{KKuUJsula4} \text { trata da confecção } \\
\text { do peso para o arremesso de peso. Os materiais utilizados foram: jornal, sacoli- } \\
\text { nha plástica, pedrinhas, meia de nylon. O implemento não apresenta qualquer } \\
\text { empecilho para sua confecção pelos alunos na escola. }\end{array}$ \\
\hline 9 & $\begin{array}{l}\mathrm{O} \text { vídeo https://www.youtube.com/watch? } \mathrm{v}=\text { Dem1dtoFEZs trata da confecção } \\
\text { do peso. Os materiais utilizados foram: bolinha plástica, gesso em pó, fita ade- } \\
\text { siva ou isolante. O implemento pode ser feito em sala de aula, possibilitando } \\
\text { uma maior interação entre os alunos e o atletismo. }\end{array}$ \\
\hline 10 & $\begin{array}{l}\mathrm{O} \text { vídeo https://www.youtube.com/watch? } \mathrm{v}=\mathrm{kbiO} 3 \mathrm{wmNKtA} \text { trata da confec- } \\
\text { ção do peso utilizando-se materiais específicos, tais como: areia fina, meia e } \\
\text { uma bolinha de plástico. O vídeo não é claro quanto às ferramentas utilizadas } \\
\text { para a confecção do implemento, mas, aparentemente, o material mais perigoso } \\
\text { é a tesoura, possibilitando que o professor o reproduza em aulas de Educação } \\
\text { Física com seus alunos. }\end{array}$ \\
\hline 11 & $\begin{array}{l}\text { O vídeo https://www.youtube.com/watch?v=v46CQYB6qPY trata da confec- } \\
\text { ção do bastão para a corrida do revezamento. Os materiais utilizados foram: } \\
\text { jornal e fita adesiva. A confecção do implemento é muito simples e pode ser re- } \\
\text { alizado em aulas de Educação Física. }\end{array}$ \\
\hline 12 & $\begin{array}{l}\mathrm{O} \text { vídeo https: } / / \text { www.youtube.com/watch? } \mathrm{v}=\mathrm{NH} 2 \mathrm{XmQ} 1 \mathrm{mqY} 8 \text { trata da confec- } \\
\text { ção das raias. Os materiais utilizados foram: fita crepe, barbante e palitinhos } \\
\text { para churrasco. As raias são de fácil confecção e, com a dica do vídeo, é possí- } \\
\text { vel adaptá-las em diferentes ambientes. }\end{array}$ \\
\hline 13 & $\begin{array}{l}\text { O vídeo https://www.youtube.com/watch?v=HwAzeXaEVaY trata da constru- } \\
\text { ção de uma barreira com garrafas pet e fita adesiva. Passível de ser feito em } \\
\text { sala de aula, o material é de fácil acesso e manuseio, apresentando riscos míni- } \\
\text { mos, considerando-se a utilização de uma tesoura. }\end{array}$ \\
\hline
\end{tabular}

Fonte: Os autores, 2017

Diferentemente da primeira categoria, os vídeos da Categoria 2 podem propiciar que os alunos construam os materiais, sozinhos ou com a mediação do professor. Nesse sentido, os materiais podem ser elaborados em sala de aula, sem, necessariamente, haver uma preocupação e uma atenção maiores com as etapas mais complexas e perigosas, já que não demandam materiais como serra elétrica, estilete, tesoura etc., como na Categoria 1. Os vídeos desta categoria, portanto, também possibilitam que os alunos se envolvam na construção de materiais em casa.

Dessa forma, percebemos que esses vídeos são ferramentas potenciais para o ensino do atletismo. Pautando-nos nos tipos de utilização das TIC no ensino, apresentados por Coll (2010), observamos que os vídeos de ambas as categorias poderiam ser utilizados como: (a) “instrumentos mediadores das relações entre professores e conteúdos (e tarefas) de aprendiza- 
gem" (p. 84), ou seja, o professor poderia construir materiais alternativos, se pautando nos vídeos, durante a fase de preparação de suas aulas; (b) "instrumentos mediadores da atividade conjunta desenvolvida por professores e alunos durante a realização das tarefas ou atividades de ensino e aprendizagem" (p. 85), ou seja, o professor e os alunos poderiam construir os materiais durante as aulas, contribuindo para a aprendizagem do atletismo; (c) "instrumentos mediadores das relações entre alunos e conteúdos (e tarefas) de aprendizagem” (p. 81), ou seja, os alunos poderiam buscar o conteúdos sobre como construir materiais alternativos, pesquisando na internet ou na base de dados aqui organizada.

Não há dúvidas de que a utilização deste tipo de material no ambiente escolar pode aproximar os alunos das especificidades dos conteúdos, conforme apontam Sebriam (2009) e Ginciene e Matthiesen (2014). Por meio dessa ferramenta, pode haver uma maior interação entre professores e alunos e destes com o conhecimento, sobre o qual comentam e compartilham.

Nisso, esses vídeos disponíveis no YoutTube têm muito a contribuir, já que, por meio deles, o contato com o conhecimento pode se tornar mais dinâmico. Silva (2011), por exemplo, revela que as imagens de um livro são estáticas, enquanto o material visual oferece imagem dinâmica, o que causa reações diferentes, sendo que a atenção empregada pelos alunos na aula é maior. Ou seja, o vídeo é uma forma descontraída para apresentar o conteúdo abordado em aula como evidencia Moran (2009):

O vídeo está umbilicalmente ligado à televisão e um contexto de lazer, de entretenimento, que passa imperceptivelmente para a sua sala de aula. Vídeo, na cabeça dos alunos, significa descanso e não "aula", o que modifica a postura, as expectativas em relação ao seu uso. Precisamos aproveitar essa expectativa positiva para atrair o aluno para os assuntos do nosso planejamento pedagógico. Mas, ao mesmo tempo, devemos saber que necessitamos prestar atenção para estabelecer novas pontes entre o vídeo e as outras dinâmicas da aula (p. 36-37).

Em linhas gerais, é possível dizer que os vídeos consistem em ferramenta extremamente útil para o ensino, ainda que seja necessário alertar para os cuidados que os professores devem adotar em sua utilização. Alguns professores o utilizam como fonte de conhecimento principal de suas aulas, excluindo a explicação sobre o assunto que está sendo abordado, o que é um erro, já que os vídeos devem ser considerados como um material auxiliar, podendo ser utilizados para ilustrar os conteúdos a partir de imagens dinâmicas (SILVA, 2011).

Os vídeos encontrados também podem ser utilizados para ilustrar os materiais que serão construídos em aula, além de incentivarem os alunos a serem protagonistas de sua própria prática fora da escola, se apropriando desses conhecimentos para construírem materiais e se envolverem com as diferentes provas do atletismo.

Entretanto, não é demais lembrar que algumas escolas não contam com infraestrutura para a projeção dos vídeos, conforme constatado por Sebriam (2009). Por outro lado, nota-se que os alunos, na maior parte das vezes, possuem celulares, tablets ou computadores, de modo que o professor pode indicar sites e canais do Youtube para consulta durante a aula ou para além dela.

De modo geral, os 28 vídeos apresentados nas Categorias 1 e 2 demonstram diferentes possibilidades para a confecção de materiais visando ao ensino do atletismo, de modo a contribuir para que a realidade do não ensino desta modalidade esportiva em escolas brasileiras seja alterada.

Embora alguns vídeos demonstrem a necessidade de aquisição (compra) de materiais, é valido ressaltar que são de baixo custo e podem ser adquiridos pela escola ou por meio de doações. Assim, nota-se que a difusão desse conteúdo por meio dos vídeos do Youtube pode 
contribuir, sobremaneira, para que o atletismo seja, de fato, ensinado nas escolas, como sugere Matthiesen (2005), uma vez que o problema de não haver material (implemento) adequado passa a ser solucionado.

Nota-se, pela análise dos vídeos, que grande parte deles, em especial, os 13 vídeos que integram a Categoria 2, demonstra possibilidades reais de confecção no próprio horário das aulas de Educação Física. Da mesma forma, embora utilizem ferramentas perfurantes, podendo acarretar certos riscos, os implementos produzidos nos 15 vídeos da Categoria 1 podem ser igualmente produzidos em aulas de Educação Física, com o auxílio do professor. Assim, são 28 as opções para a confecção de implementos adaptados/alternativos viáveis para o ensino do atletismo identificados, por esta pesquisa, no site do Youtube.

\title{
Considerações finais
}

À primeira vista, o cenário para o ensino do atletismo pode ser um tanto desanimador. Porém, os benefícios advindos da prática desta modalidade esportiva são muito recompensadores. Se não é fácil ensiná-la mediante as inúmeras dificuldades apontadas pela literatura, como a falta de espaço e de material, também não é fácil ensinar as demais modalidades esportivas, as quais passam por problemas semelhantes.

Pensar nos benefícios que o atletismo proporciona é a maior inspiração que se deve ter para se vencer as barreiras que são impostas ao seu ensino no universo escolar, tendo sido este o motivo que nos impulsionou a desenvolver esta pesquisa.

Todos os vídeos identificados nesta pesquisa e registrados neste artigo demonstram possibilidades reais para que o atletismo seja ensinado em aulas de Educação Física, a partir da utilização de implementos adaptados/alternativos.

Observamos, também, que os vídeos podem ser utilizados baseados em três tipos de lógica, quais sejam: (a) o professor utilizando os vídeos para construir materiais para suas aulas; (b) o professor e o alunos utilizando o conhecimento dos vídeos para construir materiais e ampliar o conhecimento sobre atletismo em aulas de Educação Física; (c) os alunos buscando conteúdos na internet ou na base de dados para conhecer e construir seus próprios materiais, para serem utilizados em aula ou fora dela.

Por fim, cabe evidenciar uma lacuna identificada por meio desta pesquisa. Ou seja, observou-se a inexistência de vídeos no YouTube relacionados à confecção de materiais voltados às provas de saltos, uma lacuna que poderia ser preenchida por vídeos e trabalhos futuros.

Apesar da existência de algumas barreiras em relação ao ensino do atletismo, espera-se que o professor de Educação Física, ao tentar superá-las, procure conteúdos referentes à produção de implementos adaptados, como os que registramos nesta pesquisa, encontrando no YouTube um aliado tanto para a busca como para a difusão de informações desta natureza.

\section{ABOUT YOUTUBE'S VIDEOS RELATED TO THE CONFECTION OF ADAPTED IMPLEMENTS FOR THE TEACHING OF TRACK AND FIELD IN SCHOOL}

\begin{abstract}
In order to investigate in Youtube videos about track and field adapted implements, this research had two stages: 1. identification of videos about the confection of adapted implements for the teaching of track and field; 2. tabulation of the videos, organizing them into a database. Were identified 28 videos on Youtube, being: 6 about hurdles, 4 about hammer, 6 about javelin, 2 about discus, 5 about shot, 2 about stick, 1 about track and 2 involving confection of two or more implements. The results revealed that Youtube videos can contribute as an im-
\end{abstract}


portant resource for the diffusion and creation of adapted implements using different materials that allow the expansion of the teaching of this content in school.

Key words: Track and field. Physical Education. Teaching.

\title{
SOBRE VÍDEOS DE YOUTUBE RELACIONADOS A LA ELABORACIÓN DE MA- TERIALES ADAPTADOS PARA LA ENSEÑANZA DEL ATLETISMO EN LA ES- CUELA
}

\begin{abstract}
Resumen
Con el objetivo de investigar los vídeos de Youtube concernientes a materiales adaptados sobre el atletismo, esta investigación siguió dos pasos: 1. la identificación de videos relacionados a la elaboración de materiales adaptados al atletismo; 2. la clasificación de los vídeos y la organización de una base de datos. Un total de 28 videos de Youtube fueron identificados, siendo: 6 de vallas, 4 de martillo, 6 de dardo, 2 de disco, 5 de peso, 2 de bastón, 1 de carril y 2 que envuelven la elaboración de dos o más materiales. Los resultados revelaron que los vídeos de Youtube pueden servir como un recurso importante para la difusión y elaboración de materiales adaptados, utilizando diferentes materiales que expanden las posibilidades de enseñanza de ese contenido en la escuela.
\end{abstract}

Palabras clave: Atletismo. Educación Física. Enseñanza.

\section{Referências}

COLL, C.; MAURI, T.; ONRUBIA, J. A incorporação das tecnologias da informação e da comunicação na educação: do projeto técnico-pedagógico às práticas de uso. In: COLL, C.; MONEREO, C. Psicologia da educação virtual: aprender a ensinar com as Tecnologias da Informação e da Comunicação. Porto Alegre: Artmed, 2010.

C4LPT. Top Tools for Learning 2016: Top 100 Tools for Education. Disponível em: $\leq$ http://c4lpt.co.uk/top100tools/top100-edu/>. Acesso em: 19 jul. 2017.

HOLDERBAUM, G. G. Habilidades motoras fundamentais. Lecturas, Educación Física y Deportes. Revista Digital, Buenos Aires, ano 17, n.173, out. 2012. Disponível em: < http://www.efdeportes.com/efd173/habilidades-motoras-fundamentais.htm $>$ Acesso em: 22 nov. 2015.

GINCIENE, G.; MATTHIESEN, S. Q. Utilizando o moodle na Educação Física: sobre um material didático virtual para o ensino do atletismo. Motrivivencia (CDS/UFSC), Florianópolis (SC), v. 27, p. 109, 2015.

JUSTINO, E. O.; RODRIGUES, W. Atletismo na escola: é possível? Educação Física.org., mar. 2007. Disponível em: < http://www.educacaofisica.org/wp/atletismo-na-escola-e-possivel/>. Acesso em: 27 out. 2015.

KIRSCH, A, KOCH, K.; ORO, U. Antologia do atletismo. Rio de Janeiro: Ao Livro Técnico, 1983.

LENCINA, L. A.; ROCHA JÚNIOR, I. C. Diagnóstico do atletismo escolar em Santa Maria. Kinesis, Santa Maria, n. 25, p. 71-89, 2001.

MATTHIESEN, S. Q. (Org.). Atletismo se aprende na escola. Jundiaí: Fontoura, 2005. 
Atletismo na escola. Maringá: Eduem, 2014.

. Atletismo: teoria e prática. Rio de Janeiro: Guanabara Koogan, 2007.

; GINCIENE. G. Deve-se utilizar as tecnologias da informação e comunicação em aulas de educação física? Arquivos em movimento, Rio de Janeiro, v. 10 n. 2, p. 111-128, jul./ dez. 2014.

MESQUITA, I. et al. Investigação qualitativa em desporto. Porto: Gráfica Maiadouro, 2013.

MORAN, J. M.; MASETTO, M. T.; BEHRENS, M. A. Novas tecnologias e mediação pedagógica. 16. ed. Campinas (SP): Papirus, 2009.

ORO, U. Iniciação ao atletismo no Brasil: problemas e possibilidades didáticas. In: KIRSCH, A.; KOCH, K.; ORO, U. Antologia do atletismo: metodologia para iniciação em escolas e clubes. Rio de Janeiro: Ao Livro Técnico, 1983.

PARRA FILHO, D.; SANTOS, J. A. Metodologia científica. São Paulo: Futura, 1998.

ROLIM, R.; COLAÇO, P. A escola, o atletismo e os materiais improvisados. In: CONGRESSO DESPORTO, ACTIVIDADE FÍSICA E SAÚDE: O CONTRIBUTO DA CIÊNCIA E O PAPEL DA ESCOLA, 2002, Porto. Livro de resumos.... Disponível em: < http://www.adal.pt/artigos/Jovens/atletismo_na_escola2.pdf>. Acesso em: 31 ago. 2015.

SANTOS, A. R. dos. Metodologia científica: a construção do conhecimento. 2. ed. Rio de Janeiro: DP\&A Editora, 1999.

SEBRIAM, D. C. S. Utilização das Tecnologias da Informação e Comunicação no ensino de Educação Física. 2009. Dissertação (Mestrado em Engenharia de Mídias para a Educação) - Université de Poitiers, Faculdade de Motricidade Humana de Lisboa, Universidad Nacional de Educación a Distancia de Madrid. Madrid, 2009.

SILVA, A. M. O vídeo como recurso didático no ensino de matemática. 2011. 198 p. Monografia (Mestrado em Matemática) - Universidade Federal de Goiás, Goiás, 2011. Disponível em: $\quad<$ http://http://repositorio.bc.ufg.br/tede/bitstream/tde/551/1/Dissertacao\%20Ana \%20Maria\%20da\%20Silva.pdf >. Acesso em: 18 abr. 2016.

SILVA, E. V. M.; DARIDO, S. C. O atletismo nos cursos de graduação em Educação Física. Motriz, Rio Claro, v.17 n.3, p. 525-532, jul./set. 2011.

Recebido em: 08/02/2017

Revisado em: 12/07/2017

Aprovado em: 23/08/2017

Endereço para correspondência:

saraqm@rc.unesp.br

Sara Quenzer Matthiesen 
Universidade Estadual Paulista Júlio de Mesquita Filho, Instituto de Biociências de Rio Claro, Departamento de Educação Física.

Av. 24A, n. 1515

Bela Vista

13506-900 - Rio Claro, SP - Brasil - Caixa-postal: 199 